\title{
A case of Type 1 hereditary angio-oedema
}

\author{
G N Lucas ${ }^{1}$, H Abeywickrema ${ }^{2}$, B H S Premasiri ${ }^{3}$
}

Sri Lanka Journal of Child Health, 2000; 29: 58-59

(Key words: Type 1 hereditary angioedema)

\section{Introduction}

Hereditary angioedema (HAE) is associated with a deficiency of functionally active $\mathrm{C} 1$ esterase inhibitor in serum leading to uncontrolled activation of the classical pathway of complement ${ }^{1}$ with generation of vasoactive substances and subsequent manifestations of the characteristic clinical features ${ }^{2,3}$. This biochemical abnormality is inherited in an autosomal dominant manner and immunochemical studies have defined two principal forms of this condition ${ }^{4,5}$. The predominant form, hereditary angioedema (HAE) Type 1 is characterised by decreased levels of $\mathrm{C} 1$ inhibitor protein on immunoassay and low functional C 1-inhibitor activity. Patients with hereditary angioedema (HAE) Type 2 have normal or elevated concentrations of $\mathrm{C} 1$-inhibitor protein but synthesize functionally deficient $\mathrm{C} 1$-inhibitor species ${ }^{4,5}$.

In 1969 an acquired form of C 1 -inhibitor deficiency (AAE) was described by Constanzi et $\mathrm{al}^{6}$. In this rare condition the onset of symptoms is in middle age and there are nearly always associated underlying benign or malignant B-cell lymphoproliferative disorders ${ }^{7}$. Recently an autoantibody-mediated acquired deficiency of C 1-inhibitor has been described ${ }^{8}$.

\section{Case report}

A four and a half year old boy was admitted to Lady Ridgeway Hospital in October, 1999 with painless swellings of both knees, left ankle, both wrists, lower back and dorsa of hands. The child was afebrile and swellings were non pitting and non pruritic with no overlying erythema. There was no accompanying abdominal pain. There were 3 similar episodes during the previous 6 months. There was no family history of similar episodes. There was no consanguinity. The swellings gradually disappeared over the next few days.

\footnotetext{
${ }^{1}$ Consultant Paediatrician, ${ }^{2}$ Paediatric Registrar, ${ }^{3}$ Senior House Officer, Lady Ridgeway Hospital, Colombo.
}

The total white cell count was $7.2 \times 10^{9} / \mathrm{L}$ (N 61\%, L $39 \%$ ). Haemoglobin was $12.6 \mathrm{~g} / \mathrm{dl}$. The ESR was 25 $\mathrm{mm}$ in the first hour. The $\mathrm{C} 1$ Esterase Inhibitor level was $12.19 \mathrm{mg} / \mathrm{dl}$ (normal range $15-35 \mathrm{mg} / \mathrm{dl}$ ).

The child was re-admitted to hospital in December, 1999 with similar painless non pruritic swellings. He was started on Tranexamic acid $250 \mathrm{mg}$ twice a day and this was discontinued after one month. One month after discontinuing Tranexamic acid child was re-admitted to hospital with angioedema. He was restarted on Tranexamic acid and up to date he has had no more recurrences.

\section{Discussion}

Hereditary angioedema results from a genetic deficiency of the inhibitor of the first component of complement (C 1 esterase or $\mathrm{C} 1)^{1}$. Mortality from this disease has been reported to be as high as $30 \%$, death usually being caused by airway obstruction ${ }^{2,3}$. In acute, life-threatening attacks, replacement therapy with purified $\mathrm{C} 1$ inhibitor is the treatment of choice $^{2,9}$. Two classes of drugs can be used for the prophylaxis of attacks of hereditary angioedema. The antifibrinolytic agents such as epsilon aminocaproic acid and tranexamic acid have been shown to be effective $^{10,11}$. The second group of drugs are the androgens. Postpuberty, an attenuated androgen is the drug of choice. The most widely used attenuated androgens are danazol and stanozolol, the latter being less expensive and having less masculinizing side effects $^{12,13}$. In our child tranexamic acid was used for prophylaxis.

\section{References}

1. Donaldson V H, Evans R R. A biochemical abnormality in hereditary angioneurotic oedema: absence of serum inhibitor of C 1 esterase. American Journal of Medicine 1963; 35:37-44.

2. Cicardi M, Bergamaschini L, Marasini B, Boccassini G, Tucci A, Agostoni A. Hereditary angioedema: an appraisal of 104 cases. American Journal of Medical Science, 1982; 284: 2-9. 
3. Frank M M, Gelfand J A, Atkinson J R Hereditary angioedema: the clinical syndrome and its management. Annals of Internal Medicine 1976; 84: 580-93.

4. Rosen F S, Charache P, Pensky J, Donaldson V. Hereditary angioneurotic oedema: two genetic variants. Science, 1965; 148:957-8.

5. Rosen F S, Alper C A, Pensky J, Klemperer M $\mathrm{R}$, Donaldson $\mathrm{V}$ H. Genetically determined heterogeneity of the $\mathrm{C} 1$ esterase inhibitor in patients with hereditary angioneurotic oedema. Journal of Clinical Investigation 1971; 50: 2143 9.

6. Costanzi J J, Coltman C A Jr, Donaldson V H. Activation of complement by a monoclonal cryoglobulin associated with cold urticaria. Journal of Laboratory Clinical Medicine 1969;74: 902-10.

7. Caldwell J R, Ruddy S, Schur P H, Austen K F. Acquired C 1 deficiency in lymphosarcoma. Clinical Immunology/ Immunopathology 1972; 1: 39-52.

8. Alsenz J, Bork K, Loos M. Autoantibodymediated acquired deficiency of $\mathrm{C} 1$ inhibitor. New England Journal of Medicine 1987; 316:1360-3.
9. Gadek J E, Hosea S W, Gelfand J A. Replacement therapy in hereditary angioedema: successful treatment of acute episodes of angioedema with partly purified C 1 inhibitor. New England Journal of Medicine 1980; 302: 542-6.

10. Frank M M, Sergent J S, Kane M A. Epsilon aminocaproic acid therapy of hereditary angioneurotic oedema: a double blind study. New England Journal of Medicine 1972; 286: 808-12.

11. Sheffer A L, Austen K F, Rosen F S. Tranexamic acid therapy in hereditary angioneurotic oedema. New England Journal of Medicine1972; 287: 452- 4 .

12. Gelfand J A, Sherins R J, Ailing D A. Treatment of hereditary angioedema with danazol: Reversal of clinical and biochemical abnormalities. New England Journal of Medicine 1976; 295:1444-8.

13. Sheffer A L, Fearon D T, Austen K F. Clinical and biochemical effects of stanozolol therapy for hereditary angioedema. Journal of Allergy and Clinical Immunology 1981; 68:181-4. 